\title{
Energy: territory and new landscapes scenarios
}

\author{
Maria Cristina Treu*
}

\begin{abstract}
Always in history, the shaping of new landscapes is accompanied by important economic and social changes, and the relative outcomes had great impact on the formation of a new system of relations between investment choices and planning choices, orienting the management of different options of landscapes transformations. Undoubtedly, the innovation and technology incentives have anticipated the realization of solutions with a better executive convenience and better economic results. Today, the transformations seems interested by frequently contradictory choices and by short respite solutions, because these are influenced by affairs extraneous to the regional territory characteristics. Nevertheless, there are a lot of experiences that show a farsighted environmental and landscape planning. The paper underlines the characters of the transformations, putting into evidence the hybridization factors of consolidated landscapes, the most technologized architectures, the adaptability of traditional building to energetic saving, the difficulties of adaptation to energy saving policies in construction, and the scenarios that foreshadow different spaces and times for the same context transformations. We are in an "energy transition" in which scenarios of new landscapes prevail hybrid fragmentation due to provisions by sectors and territorial contexts.
\end{abstract}

Keywords: Transition to innovation technology, Approach to landscape project, Renewable energy sources aim of planning and project tools

\section{When technologies change}

During the process of economic development, the flow of new technologies is governed by two forces: the growth of technical knowledge, which increases what it is technically feasible, and the variation of relationship between factors of production, which change opportunities for choice among alternative technics.

Ways to retrace technical changes are two. The first is analysis of the relationship between sectoral policies and transformations causing technological changes among socio-economic actors working in other regional contexts; the second is relationship between the alternative technics and new production factors that changes selecting options inducing changes on urbanized area (Molinari and Treu 1983).

About energy and information technology, technical innovation is not limited to a specific product: it spreads

*Correspondence: mariacristina.treu@polimi.it

Politecnico di Milano, Dipartimento di Architettura e Studi Urbani, Via Bonardi 3, 20133 Milan, Italy involving more productive sectors and, over time, citizen's behaviour and lifestyles. It suggests us a specific role of energy policies affecting territorial transformation processes and the use of urban areas interpretable through landscape.

Today, we face signs of change affecting economic sectors involving the cognitive apparatus skills, that affects local contexts: agricultural territories, densely built urban centres, free spaces in peri-urban areas.

These marks indicate a phase of development based on a multifactorial approach that integrates multiple energy sources into production processes and compares quantitative and qualitative evaluation parameters into programming and planning choices.

Economic development determines an increase in energy consumption (Table 1); this increase suggests that, in future, it will not be enough to meet demand, despite a more careful use, a steady decline in energy consumption per unit product and performance of products.

Moreover, beyond institutions and monopolies affecting research and the management of energy sources, 
Table 1 World energy demand on milion tonne oil equivalent. Source: Ranci (2011)

\begin{tabular}{llll}
\hline Energy sources/years & $\mathbf{1 9 9 0}$ & $\mathbf{2 0 0 5}$ & Prevision 2030 \\
\hline Coal & 2.216 & 2.892 & 4.890 \\
Natural gas & 1.676 & 2.354 & 3.560 \\
Petroleum & 3.216 & 4.000 & 5.010 \\
Nuclear & 525 & 721 & 960 \\
Hydroelectric & 185 & 251 & 400 \\
Renewable & 35 & 61 & 370 \\
\hline
\end{tabular}

the economic sustainability objectives (resources optimization) and environmental compatibility (increased use of renewable resources) require budgets that control accessibility to the different energy sources.

It's important, to assess risks associated with the cost of research and extraction, the concentration of energy flows' monopolies, the political instability of the major exporters, the need to ensure security of supply and the monitoring of pollution levels associated with the use of fossil energy sources.

Compared to ductility of oil and its derivatives, there are: the natural gas monopoly, this in large quantities only in Russia; difficulties in managing its delivery (through networks crossing territories of regions prone to tension) and its pricing.

Renewable energy sources, managed locally, can improve the security of energy supply, even if they have difficulties related to the costs of installations and storage of energy produced; they can help reduce greenhouse gas emissions and achievement of other environmental purposes; these can insert competitiveness in the market through new companies and development of new specialized industrial sectors although, as it's recognized in the "2020 climate \& energy package", they require the use of incentive mechanisms.

Furthermore, even if according to International Energy Agency estimates, the world's energy need in the world is met by renewable sources to $13 \%$, it will continue to go up, it will not be the same for the percentage of Renewable Energy Sources (FER) on global demand, which is also increasing (Ranci 2011).

Perhaps the only exception occurs in Europe where it is expected that only in 2030 the percentage of energy needs met by renewable energy will be about $20 \%$. Among renewable sources, hydropower will continue to meet over $80 \%$ of demand, while the production of solar energy, biomass, wind and geothermal, albeit characterized by excellent performance in terms of growth, will satisfy small percentages.
Conservative policies of production processes with incentives and disincentives are not sufficient for the expansion of renewable energy sources on planet: it requires a process that, on one side, integrates the techno-ecological approach introducing new energies in productive sectors by replacing and renewing the existing mining installations and equipment, and also that, promotes a cultural change that can affect the behaviour of individuals (Ruffolo 1985).

\section{The energy transition and the landscape design approach}

This transition process from a production linked to fossil fuels towards the growing use of renewable sources is called the energy transition (Odun 1963; Rifkin 2011). The most obvious consequence of these changes, in terms of urban planning, is detectable in a different organization of urbanized and inhabited spaces.

This lead to, in addition to changes in production and use of different energy sources, how local communities recognize themselves in the landscape: an aspect that drives public and private choices to the introduction of renewable energy sources, adopting approaches that promote the redevelopment project of degraded landscapes, and the construction of new landscapes.

The concept of transition combines the reality-what is already there and what can be seen as a result of the installation of renewable energy facilities-and future opportunities requiring to converge landscape project with energy policies.

It is the issue of integration of landscape with sectoral policies in a central role, and, in particular, the opportunity to integrate landscape in promotion policies of renewable sources of energy, involving crosswise like a frame (frame, shape, texture, mood or perception) with different temporality, interventions in productive sectors and in urbanized areas.

The role of landscape in sectoral policies, even when they don't deal directly with landscape, is to introduce an interpretative paradigm that can be used as a tool supporting technological innovations in according with historical and cultural character of each context.

Furthermore, energy policies address the local business through public and private choices, which promote the same policies with incentives and disincentives, and, therefore, the integration of landscape in energy policies is a practicable hypothesis for greater environmental compatibility, with characters and resources of each local context.

So, to face institutionally the relationship between energy and territory in planning policies, should be done interventions affecting the implementation of energy 
policies through principles of territorial spatial organization resorting to the narrative of landscape.

Territory and landscape, therefore, can constitute a single common field of shared knowledge: physical and social environment in which technical usefulness and quality of design choices have to be compared.

In the belief that the project is a synthesis of the complexity of phenomena to be tackled, an interpretation of it is the organization of physical and environmental components; of social options in local communities, and a proposal for solutions, translatable in a simple and understandable language.

Moreover, the territory, as the landscape, cannot be analysed through visible characters and aesthetic categories, nor evading aspects that refer to physical and hydrological characteristics, to work of man and his history, the enhancement of resources and bioclimatic changes.

Territory and landscape are the products of geomorphological changes and people's activities, never directly determined by a single plan: the plan, as every project and program, contributes to the territory organization and the landscape composition, insofar it intercepts and influence the multitude of environmental and behavioural factors.

The landscape project is a process: the result of ecosystem and territorial dynamics, influenced by policies and by collective and private actions and economic and social choices of actors and stakeholders.

Therefore, the FER must promote a technological approach taking into account features of territory and landscape, offering tools to analyse spatial relationships between different factors and aiming to communicate the content of innovation that has to deal with the effects of transformation, that is, an exchange of knowledge and expertise from technology to landscape and vice versa.

\section{Renewable energy sources and territory}

History is marked by changes announcing new development scenarios with a sequence of events which, although at different times and in different sectors, are intended to transform the set of economic and social structures, the territory and the landscape of our territorial and urban systems.

These are factors affecting production processes, the morphology of the settlement types, social behaviour and, more generally, economic relations between different regions and between states. At the beginning these are signs of innovation acting locally, with frequencies and mode appearing episodic, but then they produce and realize in effects and system modifications that seem unexpected.

Until the Industrial Revolution, energy produced by human and animals labour affect the territory geomorphology; after the industrial revolution, energy produced by burning coal and then by oil and gas transforms relations between territories of regions and big conurbation settlement. Changes can be read in compact urban contexts, in border urban areas, in farming areas and in hilly and mountain areas.

These changes are the result of projects involving the addition of single elements to existing buildings or to replace the entire involucre with very different solutions; they are the energy production facilities and heat localized in landlocked free areas and on the outskirts of settlements and agricultural lands; they are the colours of agricultural crops for energy production such as rapeseed fields and landscape change due to solar farms.

Effects include the hybridization of consolidated landscapes, despite the search for solutions for the recent building heritage, as well as the technical norms of single municipalities; the introduction of landscape mitigation for biogas plants; new materials and new products compatible also with traditional buildings and environments.

In brief, they are interventions which foreshadow new landscape scenarios, which are already in some of the Mediterranean islands, in which the changes of agricultural areas and densely built zones, will be involved, in later times, transforming, seamlessly, spaces and contexts.

Today, the incentives for technological innovations have anticipated and guided the solutions development which require a greater ease of installation; and there are more economic yields, in some cases sacrificing, or overshadowing the search for more consistent interventions on the context, easy to maintain, and more resilient to the recovery of other uses.

The installation of photovoltaic devices on buildings is becoming a widespread practice: it is based on a small and medium-size model, it can be placed wherever is permitted by construction characteristics, exposure and the absence of restrictions on landscape.

Next to this practice is also growing the model that favours the installation of photovoltaic elements on large surfaces like those on roofs of exhibition centres and malls or industrial buildings.

Economies of scale and organizational advantages inherent the concentration of photovoltaic modules in a single site are obvious, like the attractiveness that these systems, if and until they are supported by public incentives and tax breaks, have exercised against Italian and foreign investors.

This explains the growth of financial companies, real estate and specialized companies in managing insurance agreements with local operators and authorities and, at the same time, concerns of the organizations working for 
environment and landscape against the spread of practices without project.

The European Commission text, the 29th November 2000 Green Paper titled "Towards a European Strategy for Energy Supply", proposes biodiesel instead of diesel and focuses on the huge potential of agricultural and forest residues, as well as energy crops.

Biofuels obtained by efficient and sustainable systems, such as those derived from rapeseed and sunflower seeds or from beet and wheat, don't require a distribution system and diversified infrastructure, unlike the biomass systems.

In these cases, installations are generally located near the farms, require access roads and proximity to network of power lines, they are systems with lower yields and oversized for energy and heat production.

Besides, there are experiences that require programming and planning which integrates tangible and intangible skills, those that require a process of rationalization and innovation of production processes and a change in designing buildings and entire urban areas, which require changes in behaviour and lifestyles of citizens.

We can add to these approaches experiences of sustainable neighbourhoods, and passive buildings that become energy producers, these experiences are verifiable in many cities not only European, related to new production chains, recycled materials by conventional construction, and other manufacturing sectors, with an active role of the inhabitants.

In the background there is the thorny issue of environmental certificates allowing richer countries to monetize their disengagement and their delay for deadlines of pollutant emissions reduction.

It is a matter that could change when China and, above all, United States,-as is trying to do President Barack Obama before the end of his mandate-will accept the Kyoto Protocol clauses drawn up on 11 December 1997.

\section{The role of plan and project tools}

The creation of new landscapes is always accompanied not only by economic and social changes, even by laws going to affect the programming of public and private investments, as well as planning and design.

However, in this phase of energy transition, contradictions between decisional levels and design tools are not able to support technological innovation with virtuous outcomes in the construction of new scenarios of landscape.

In Europe the greatest progress in testing phase and deployment of renewable energy sources come from the European Commission laws, as early as 1995 with the White Paper "An energy policy for the European Union."
It is the first text of the European Commission which aimed to promote greater competitiveness of its member states economy, safety of energy supplies and environmental protection, in addition to regulatory and financial instruments.

The following Green Paper, "A European Strategy for Sustainable, Competitive and Secure Energy", better specified the goals to reduce dependence on imports and variability in oil and gas prices and to cope with climate change, increased demand and obstacles placed by governments and the opposition from citizens to new installations.

In 2008, the European Union promoted the "energy and climate package" that, in accordance with the Kyoto Protocol, planned to bring the production of energy from renewable sources to $20 \%$ by 2020 .

This is the only benchmark to be checked at next deadline, as result of measures took for technological innovation in several sectors, such as the reduction of car emissions, the energy savings in properties and civil and industrial plant.

Today, in spite of a Community policy which promotes cross-cutting initiatives such as the "energy and climate package", and the existence of a European Observatory for Energy, experiences in different countries is characterized by a program that, according to the territories/ settlements has a different growth of renewable energy sources (Table 2) and that are impacted, especially in the distribution of investment, by interests of conventional energy managers.

Furthermore, the lack of attention given to territories and landscapes features, where installations should be located, it is assigned to the member states, regional authorities and municipalities, which manage their skills on planning and landscapes design with different interpretations of the European Landscape Convention.

However, new energy sources represent an opportunity for the rehabilitation of degraded environments and to design new forms of landscape.

Table 2 Power installable on MWp from 205 to 2030 on Italy. Source: CNES

\begin{tabular}{lllll}
\hline Type of territory/years & $\mathbf{2 0 0 5}$ & $\mathbf{2 0 1 5}$ & $\mathbf{2 0 2 0}$ & $\mathbf{2 0 3 0}$ \\
\hline Continuous urban fabric & 2.090 & 3.440 & 5.620 & 9.720 \\
Discontinuous urban fabric & 2.670 & 4.400 & 7.180 & 12.430 \\
Industrial or commercial areas & 290 & 900 & 1.520 & 2.710 \\
Roads and railways & 7 & 20 & 40 & 70 \\
Doks & 9 & 30 & 50 & 90 \\
Seminars in non-irrigated areas & 390 & 1.060 & 1.920 & 3.200 \\
Such installable power (MWp) & 5.500 & 9.800 & 16.300 & 28.200 \\
\hline
\end{tabular}


About this, it's more appropriate to recall some experiences that, in Italy, can highlight role and difficulty in programming and planning of FER.

The last few years, the focus of the territorial and urban planning instruments are focused on two themes: the protection of agricultural areas, and the reduction of building areas.

It can be assumed that these issues would affect the awareness of Italian dependence on food products imports, environmental roles on earth and the importance of free and green areas in terms of landscape.

In the case of renewable energy sources, planning collides with housing income and prices of agricultural products and, while sunflowers and rapeseed crops have a landscape impact that, in certain seasons, are enriched with new colours, corn and inedible wheat crops have a negative impact on food production.

Fields for photovoltaic panels facilities subtract a large amount of flat and fertile soil and alter the landscape, despite the imposition of vegetable mitigations that in some municipalities are prescribed by zoning regulations.

Furthermore, they are promoted by economic and financial operators who can convince farmers to renounce to their land, giving up their activities, due to the price volatility of agricultural products.

To all this we must add the loss of material culture and, for corn production and no-food wheat, the impoverishment of soil fertility due to its over-exploitation.

Simultaneously, the agricultural landscape is affected by dissemination of biogas facilities often oversized compared to energy requirements, and the production of heat by the farms.

While the excess energy goes into the public power grid, the excess heat is dissipated into the atmosphere: there are experiences that integrate these systems in a landscape project that, in addition to balance supply and demand, uses systems at a size that can fit into a corporate structure.

For biogas facilities, there is also a discrepancy between the skills of the province (Local Health Agency) and those of the municipality that encourage the opposition from local population: for example, a biogas system using excess heat to handle contiguous greenhouses, obtained approval from province, couldn't get approval, despite the quality of the proposed solution, by the municipality that has the final responsibility on the use of soil, since it is not allowed the possibility to monitor the quality and origin of wood products that will feed the system burner.

About interventions in urban areas, integrated planning, and protection of territory and landscape, should encourage the coverage of large existing surfaces, such as commercial complexes and industrial buildings and, above all, it could also promote the redevelopment of many degraded areas.

Finally, there is the technological innovation applied to building components with environmental and landscape performance, from concrete able to absorb rainwater and provide visibility to small wind turbines to be installed in landscape sensitive areas, recycled materials tiles, as some types of glass, and with specific energy saving performance, adaptable also to historical centres buildings.

Overall, all products, together with the plant engineering renewal, will have to adapt a building heritage which, for more than $50 \%$, requires consolidation measures and is placed in the low average energy classes.

Italy gets to surprise with big projects, such as the Italian building at Shanghai, a structure that produces energy and uses excellent Italian products, but it is not so for planning which requires increased efficiency avoiding indiscriminate distribution of public resources.

There aren't indications by a Monitoring Centre able to produce periodic sector reports, industry-specific budgets, able to guide financial incentives to privates and dimensioning and location of the production facilities of FER.

Environmental target requires, in addition to a streamlining of environmental consumption, a redistribution of energy production to reduce service costs for population and companies.

Among private investors receiving incentives from the national tax system, there are often foreign investors and, therefore, must be scheduled a return of energy production quotas for the management of public services.

The integration of an observatory of sector budgets with an effective energy policy requires a cultural change which integrates the conservative approach to ecology with the techno-ecology, i.e. the rationalization and innovation to reduce energy consumption, a creative approach which requires more culture and more creativity.

\section{Authors' contributions}

The author read and approved the final manuscript.

\section{Authors' informations}

The author is full professor in urban planning at Politecnico of Milan, where she was Director of Documentation Center, Prorector of Politecnico and Vice President Politecnico Fondation. She was teacher in a course of lectures on the Environmental Planning and, recently, on the Urban design and Urban Landscape.

Her more recent publications are "Città, Salute e Sicurezza", Politecnica Series of Maggioli Editor, 2009, "Per una Città Socievole”, La città e l'altra città Series, 2014 and "Urban safety and security", La città e l'altra città Series, Maggioli Editor, 2015. Up to date she was codirector of La città e l'altra città Series, President of Fiorella Ghilardotti Association about immigration questions and consilior of Metropolitan Agency of Public Local transport (TPL). 
Competing interests

The author declare there is no competing interests.

\section{Availability of data and materials}

Not applicable.

\section{Consent for publication}

Not applicable.

Ethics approval and consent to participate

Not applicable.

\section{Funding}

Not applicable.

\section{Publisher's Note}

Springer Nature remains neutral with regard to jurisdictional claims in published maps and institutional affiliations.
Received: 22 August 2018 Accepted: 17 October 2018

Published online: 26 October 2018

\section{References}

Molinari C, Treu C (1983) Quando cambiano le tecnologie". Sindacato'80, mensile della Filca Cisl, anno II, n11, p. 6-9, with reference to Salter, mathematical model concerning connections among technological innovations and manufacturing processes; another reference to Salter model on, Garofalo G, Pedone A (2000) Distribuzione, re-distribuzione e crescita: gli effetti delle diseguaglianze distributive. Franco Angeli, Milano Odun EP (1963) Ecology. Holt Rinehart and Wiston, New York

Ranci P (2011) II sistema energetico. II Mulino, Bologna

Rifkin J (2011) The third industrial revolution: how lateral power is trasforming energy, the economy and the world. St Martin's Press, New York Ruffolo G (1985) La qualità sociale. II Mulino, Bologna

\section{Submit your manuscript to a SpringerOpen ${ }^{\circ}$ journal and benefit from:}

- Convenient online submission

- Rigorous peer review

- Open access: articles freely available online

- High visibility within the field

- Retaining the copyright to your article

Submit your next manuscript at $\boldsymbol{\nabla}$ springeropen.com 